\title{
Anatomic and Embryologic Analysis of the Dural Branches of the Ophthalmic Artery
}

\author{
(D) S. Bonasia, (D). Smajda, (D) G. Ciccio, and (D)T. Robert
} O- $=$

\begin{abstract}
SUMMARY: The ophthalmic artery has one of the most fascinating embryologic developments among the craniofacial arteries. Most of the ophthalmic artery orbital branches develop from the formation and regression of the stapedial artery and share their origin with dural branches of the ophthalmic artery. The concomitant embryologic development of the ophthalmic artery and middle meningeal artery explains adequately the important varieties of anastomosis between these 2 arteries. It also explains the presence of many dural branches from the ophthalmic artery. In this review, we focused on dural branches of the ophthalmic artery with the description of rare variations possible, in particular the ophthalmic artery origin of the middle meningeal artery and the ophthalmic artery origin of the marginal tentorial artery.
\end{abstract}

ABBREVIATIONS: $\mathrm{dAVF}=$ dural arteriovenous fistula; $\mathrm{ECA}=$ external carotid artery; MMA = middle meningeal artery; MTA = marginal tentorial artery; OA $=$ ophthalmic artery; PDOA = primitive dorsal ophthalmic artery; PVOA = primitive ventral ophthalmic artery; SA = stapedial artery

$\mathbf{T}$ he ophthalmic artery $(\mathrm{OA})$ is a very fascinating artery for its complex embryologic development and also for numerous vascular anastomoses developed with branches of the external carotid artery (ECA). The role of the OA in supplying the dura is not well-known, but the understanding of the dural function of the OA and also of its possible variations is a cornerstone for surgical and endovascular treatment of dural pathologies (dural arteriovenous fistulas (dAVFs), skull base meningiomas, chronic subdural hematoma embolization). In this review, we will focus on the dural branches of the OA with rare variations, in particular the OA origin of the middle meningeal artery (MMA) and the OA origin of the marginal tentorial artery (MTA). All procedures performed in the studies involving human participants were in accordance with the ethical standards of the institutional and/or national research committee and with the 1964 Helsinki Declaration and its later amendments or comparable ethical standards.

Received July 18, 2020; accepted after revision September 17.

From the Department of Neurosurgery (S.B., T.R.), Neurocentral of Southern Switzerland, Regional Hospital of Lugano, Lugano, Switzerland; University of Southern Switzerland (S.B., T.R.), Lugano, Switzerland; and Department of Interventional Neuroradiology (S.S., G.C.), Rothschild Foundation Hospital, Paris, France.

Please address correspondence to Sara Bonasia, MD, Department of Neurosurgery, Neurocentral of Southern Switzerland, Regional Hospital of Lugano, Via Tesserete 46, CH-6903 Lugano, Switzerland; e-mail: sara.bonasia@gmail.com

- Indicates open access to non-subscribers at www.ajnr.org

Indicates article with online supplemental data.

http://dx.doi.org/10.3174/ajnr.A6939
Informed consent was obtained from all individual participants included in the study.

\section{History}

Meyer, ${ }^{1}$ in 1887 , considered a pioneer in the orbital vascular anatomy, was the first to precisely describe all branches of the ophthalmic artery, including its dural territory. A few years before, Curnow, ${ }^{2}$ in 1873, had already described 3 cadaveric cases of variations in the origin of the OA. One of these 3 cases was the first description of an OA origin of the MMA. With the advent of the DSA, Kuru, ${ }^{3}$ in 1967, gave a detailed description of the OA meningeal branches, and after him, a few authors ${ }^{4-10}$ focused on the variants of the OA and the MMA. Lasjaunias et $\mathrm{al}^{8,9,11}$ gave their crucial contribution to the comprehension of the orbital and meningeal vascular supply, combining their knowledge of the embryology with an accurate angiographic analysis. The last author to give a comprehensive description of dural vascularization was Rhoton, ${ }^{12}$ in 2002, based on a large cadaveric dissection experience.

Embryology. The OA starts its development when the embryo is about $4 \mathrm{~mm}$ and reaches its adult configuration at about $40 \mathrm{~mm}$. Its development is strictly connected with the arterial embryology of the primitive ICA, the stapedial artery (SA), and the pharyngeal artery system. In the past, 2 authors were interested in the comprehension of the complex events of the OA formation: Padget, ${ }^{13}$ who formulated her theory after the dissection of 22 embryos, and Lasjaunias et $\mathrm{al}^{11}{ }^{11}$ who added to Padget's 


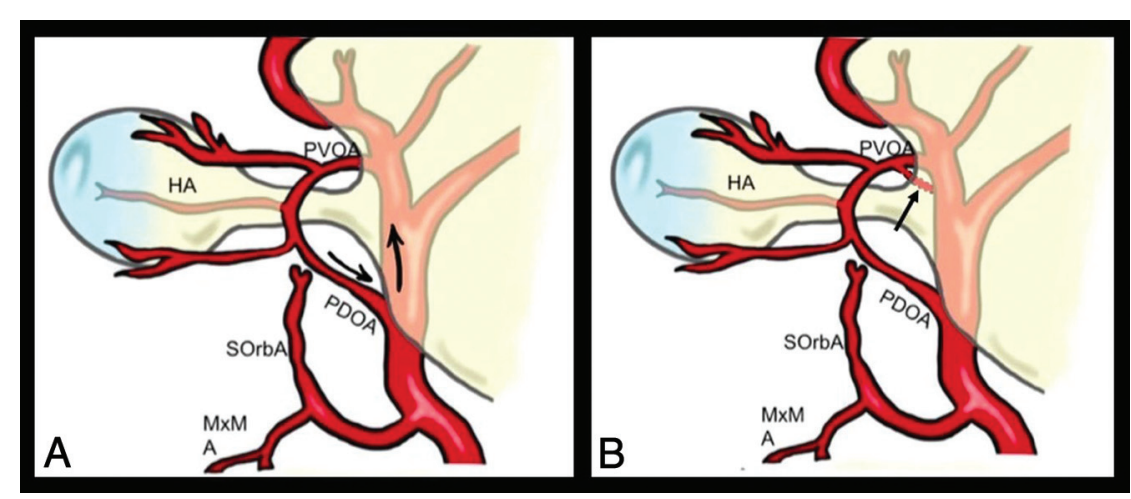

FIG 1. Theories of Padget and Lasjauinias et al about OA origin migration. When the embryo is about $18 \mathrm{~mm}$, the OA reaches its definitive origin on the supraclinoid ICA. This phenomenon is explained by Padget ${ }^{13}$ by the cranial elongation of the ICA during this stage with the consequent movement of the PDOA origin (black arrows in A). On the other hand, Lasjaunias et al ${ }^{11}$ hypothesized the presence of an intradural anastomosis between the PVOA and the primitive ICA (black arrow in $B$ ) in correspondence with the future origin with successive regression of the original stem. HA indicates hyaloid artery; $M \times M$, maxillo-mandibulary artery; SOrbA, supraorbital artery.

supraorbital artery. The supraorbital artery enters the orbit through the superior orbital fissure and gives off 2 branches: the ethmoid nasal and the lacrimal artery.

The relationship among the PDOA, the PVOA, and the SA is most important in the last 2 stages (stage 5: embryo of $20 \mathrm{~mm}$; stage 6 : embryo of $40 \mathrm{~mm}$ ). During stage 5, an anastomotic ring appears around the optic nerve, formed by the anastomosis among the PVOA, the PDOA, and the supraorbital artery (through the ethmoid nasal artery). However, in stage 6, this ring is ventrally interrupted to give the definitive configuration of the OA. The part of the anastomotic ring that regresses is crucial to determine which of the 2 primitive OAs persists to form the adult $\mathrm{OA}$. According to Padget, ${ }^{13}$ it is the PDOA

knowledge an accurate angiographic evaluation. These authors agreed that the definitive features of the OA depend mostly on 2 embryonic arteries, the primitive dorsal ophthalmic artery (PDOA) and the primitive ventral ophthalmic artery (PVOA).

According to Padget's theory, ${ }^{13}$ the embryologic development of the OA could be divided into 6 stages, which are summarized in the Online Supplemental Data. The PDOA appears when the embryo is about $4-5 \mathrm{~mm}$ (stage 1), originating from the bifurcation of the primitive internal carotid artery. In the following stage 2 (9-mm embryos), while the PDOA enlarges through the optic cup as plexiform channels, the PVOA arises from the cranial division of the primitive ICA. The PDOA and PVOA are then destined to elongate following the ventral shifting of the optic cup and the dorsal shifting of the cerebral hemispheres. In embryos of 14-17 mm, one can note the appearance of 2 branches from the PDOA artery: the primitive hyaloid artery and the common temporal ciliary artery (future lateral posterior ciliary artery). The PVOA gives off, at the same time, the common nasal ciliary artery (future medial posterior ciliary artery).

In the embryo of about $18 \mathrm{~mm}$ (stage 3 ), the OA undergoes a process that will cause migration of its origin on the supraclinoid ICA. This phenomenon is explained by Padget by the cranial elongation of the ICA during this stage with the consequent movement of the PDOA. On the other hand, Lasjaunias et $\mathrm{al}^{9,11,14}$ explained this migration by the presence of an intradural anastomosis between the PVOA and the primitive carotid artery in correspondence of the future origin, with consequent regression of the original stem. The 2 theories of OA origin migration are illustrated in Fig 1.

From stage 1 to 4 , another artery grows at the same time and contributes to the adult configuration of the orbital arteries: the SA. In the first stages, the optic cup is supplied on its ventral side by the primitive maxillary artery. However, it starts to regress at the end of stage 2 , to be substituted by the SA in its orbital territory. This latter gives off 2 branches that follow the 3 divisions of the trigeminal nerve: the maxillomandibular artery and the that persists, with consequent PVOA proximal regression. On the other hand, Lasjaunias et $\mathrm{al}^{9,11,14}$ wrote that the distal portion of the PDOA regresses and its proximal part is destined to form the future inferolateral trunk. Thus, their opinion is that the PVOA mostly contributes to the formation of the definitive OA.

At the same time, the extraorbital part of the supraorbital artery regresses to let the lacrimal artery to be annexed by the OA.

\section{Dural Branches of the OA}

Different dural branches of the OA and their possible anastomoses with other dural arteries are listed in Table 1; their respective dural territories are illustrated in Fig 2.

Deep Recurrent Ophthalmic Artery. The deep recurrent ophthalmic artery arises from the first segment of the OA and has a recurrent course through the medial part of the superior orbital fissure. This artery supplies the dura of the lateral wall of the cavernous sinus. It consistently anastomoses with the anteromedial branch of the inferolateral trunk and often with the cavernous branch of the middle meningeal artery and with the accessory meningeal artery. It is considered as a remnant of the primitive dorsal ophthalmic artery. ${ }^{9}$

Superficial Recurrent Ophthalmic Artery. The superficial recurrent ophthalmic artery is a meningeal branch that takes its origin from the proximal part of the lacrimal artery or directly from the second segment of the OA.,11,15 This artery passes through the lateral part of the superior orbital fissure to reach the dura over the anterior clinoid process and the cavernous sinus roof. ${ }^{3,16}$ The superficial recurrent ophthalmic artery also supplies the intradural part of the third and fourth cranial nerves. This artery is the orbital remnant of the supraorbital branch of the stapedial artery. $^{11}$

Posterior Ethmoidal Artery. The posterior ethmoidal artery is a small meningeal branch that originates from the third segment of the OA, which exits the orbit through the posterior ethmoidal 
Table 1: Different dural branches of the OA with their respective supply and anastomoses

\begin{tabular}{|c|c|c|c|c|c|}
\hline OA Branches & $\begin{array}{l}\text { Origin from } \\
\text { the OA }\end{array}$ & Foramen & Dural Territory & $\begin{array}{c}\text { Possible } \\
\text { Anastomosis }\end{array}$ & $\begin{array}{c}\text { Clinical Consequences in Case } \\
\text { of Embolism }\end{array}$ \\
\hline $\begin{array}{l}\text { Deep recurrent } \\
\text { OA }\end{array}$ & First segment & $\begin{array}{l}\text { Superior orbital } \\
\text { fissure }\end{array}$ & $\begin{array}{l}\text { Superior orbital } \\
\text { fissure (lateral } \\
\text { part), sphenoid } \\
\text { wing }\end{array}$ & $\begin{array}{l}\text { Inferolateral trunk } \\
\text { (ICA) }\end{array}$ & Cerebrovascular accident \\
\hline $\begin{array}{l}\text { Superficial } \\
\text { recurrent OA }\end{array}$ & $\begin{array}{l}\text { Second } \\
\text { segment }\end{array}$ & $\begin{array}{l}\text { Superior orbital } \\
\text { fissure }\end{array}$ & $\begin{array}{l}\text { Anterior clinoid } \\
\text { process } \\
\text { Lesser sphenoid } \\
\text { wing } \\
\text { Middle fossa } \\
\text { (anteromedial } \\
\text { portion) }\end{array}$ & $\begin{array}{l}\text { Posterior ethmoidal } \\
\text { artery } \\
\text { MMA (anterior } \\
\text { division) } \\
\text { Medial tentorial } \\
\text { artery (ICA) }\end{array}$ & $\begin{array}{l}\text { Cerebrovascular accident, loss } \\
\text { of vision }\end{array}$ \\
\hline $\begin{array}{l}\text { Anterior ethmoidal } \\
\text { artery }\end{array}$ & Third segment & $\begin{array}{l}\text { Anterior } \\
\text { ethmoidal canal }\end{array}$ & $\begin{array}{l}\text { Anterior convexity } \\
\text { (anterior } \\
\text { meningeal artery) } \\
\text { Anterior cranial } \\
\text { fossa (medial } \\
\text { third) } \\
\text { Anterior falx cerebri } \\
\text { (anterior falcine } \\
\text { artery) }\end{array}$ & $\begin{array}{l}\text { Contralateral } \\
\text { anterior } \\
\text { ethmoidal artery } \\
\text { Bilateral MMAs } \\
\text { Posterior } \\
\text { ethmoidal artery } \\
\text { Olfactory branch } \\
\text { (ACA) }\end{array}$ & \\
\hline $\begin{array}{l}\text { Posterior } \\
\text { ethmoidal artery }\end{array}$ & Third segment & $\begin{array}{l}\text { Posterior } \\
\quad \text { ethmoidal canal }\end{array}$ & $\begin{array}{l}\text { Anterior cranial } \\
\text { fossa (medial } \\
\text { third) } \\
\text { Anterior clinoid } \\
\text { process } \\
\text { Chiasmatic groove }\end{array}$ & $\begin{array}{l}\text { Contralateral } \\
\text { posterior } \\
\text { ethmoidal artery } \\
\text { Anterior ethmoidal } \\
\text { artery } \\
\text { MMA (anterior } \\
\text { division) }\end{array}$ & \\
\hline
\end{tabular}

Note:-ACA indicates anterior cerebral artery.

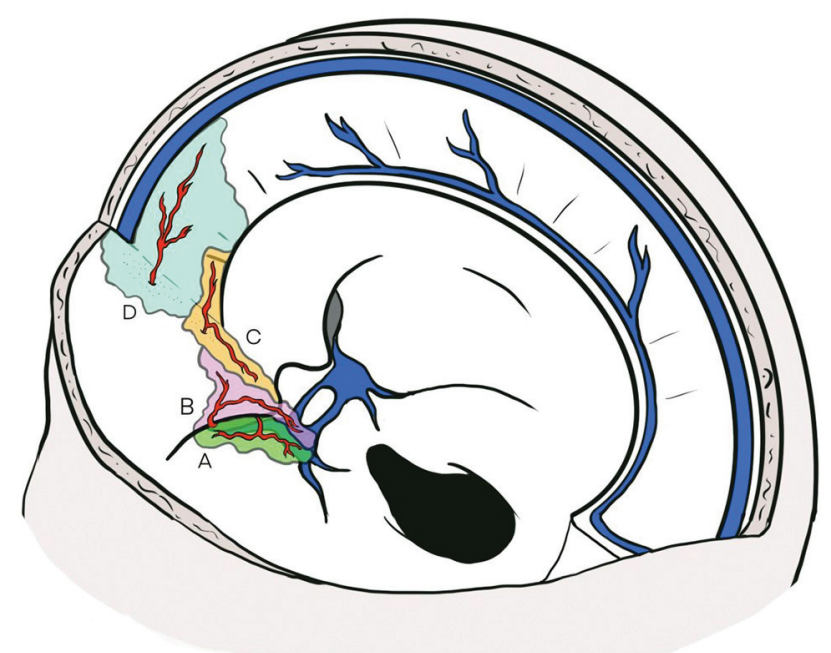

FIG 2. Dural territories of OA branches. A, Territory of the deep recurrent ophthalmic artery (green), which exits from the medial part of the superior orbital fissure and supplies the dura of the lateral wall of the cavernous sinus. $B$, Dural territory of the superficial recurrent ophthalmic artery (pink), which passes through the lateral part of the superior orbital fissure to reach the dura over the anterior clinoid process and the cavernous sinus roof. $C$, The posterior ethmoidal artery (orange) passes through the posterior ethmoidal canal to reach the dura of the planum sphenoidale, the posterior cribriform plate, and the anterior clinoid process. $D$, The anterior ethmoidal artery (light blue) passes through the anterior ethmoidal canal, and its meningeal territory consists of the anterior part of the cribriform plate, the medial part of the orbital roof, and the anterior third of the falx cerebri. canal. ${ }^{15}$ Its average diameter is $0.4 \mathrm{~mm}$, and it is usually in balance with the diameter of the anterior ethmoidal artery. ${ }^{17}$ This artery supplies the dura of the planum sphenoidale, the posterior cribriform plate, and the anterior clinoid process. ${ }^{11}$ Martins et al, ${ }^{16}$ in 2005 , showed that the posterior ethmoidal artery often anastomoses with dural branches of the internal carotid artery, middle meningeal artery, and anterior ethmoidal artery. When absent (approximately 20\%), its meningeal territory is taken over by these 3 other arteries. ${ }^{16}$

Anterior Ethmoidal Artery. The anterior ethmoidal artery is a more constant artery, which has been found in $>90 \%$ of the orbits if the OA crosses over the optic nerve, and in $80 \%$ of cases when the $\mathrm{OA}$ crosses under the nerve. It originates from the distal part of the OA and could give off from 1 to 5 little branches that pass through the anterior ethmoidal canal. Other than the nasal septum and nasal fossa, its meningeal territory is limited to the anterior part of the cribriform plate, the medial part of the orbital roof, and the anterior third of the falx cerebri. The anterior ethmoidal artery gives off a branch, well-described angiographically by $\mathrm{Kuru}^{3}{ }^{3}$ in 1967 , along the falx cerebri, called the anterior falcine artery or the artery of the falx cerebri. This anterior falcine artery could be present bilaterally, but usually 1 side is predominant. If the anterior ethmoidal artery is well-developed, it can give off some branches called "anterior meningeal arteries," that differ from the anterior falcine artery because of their paramedial course and can supply the dura of the anterior convexity. 


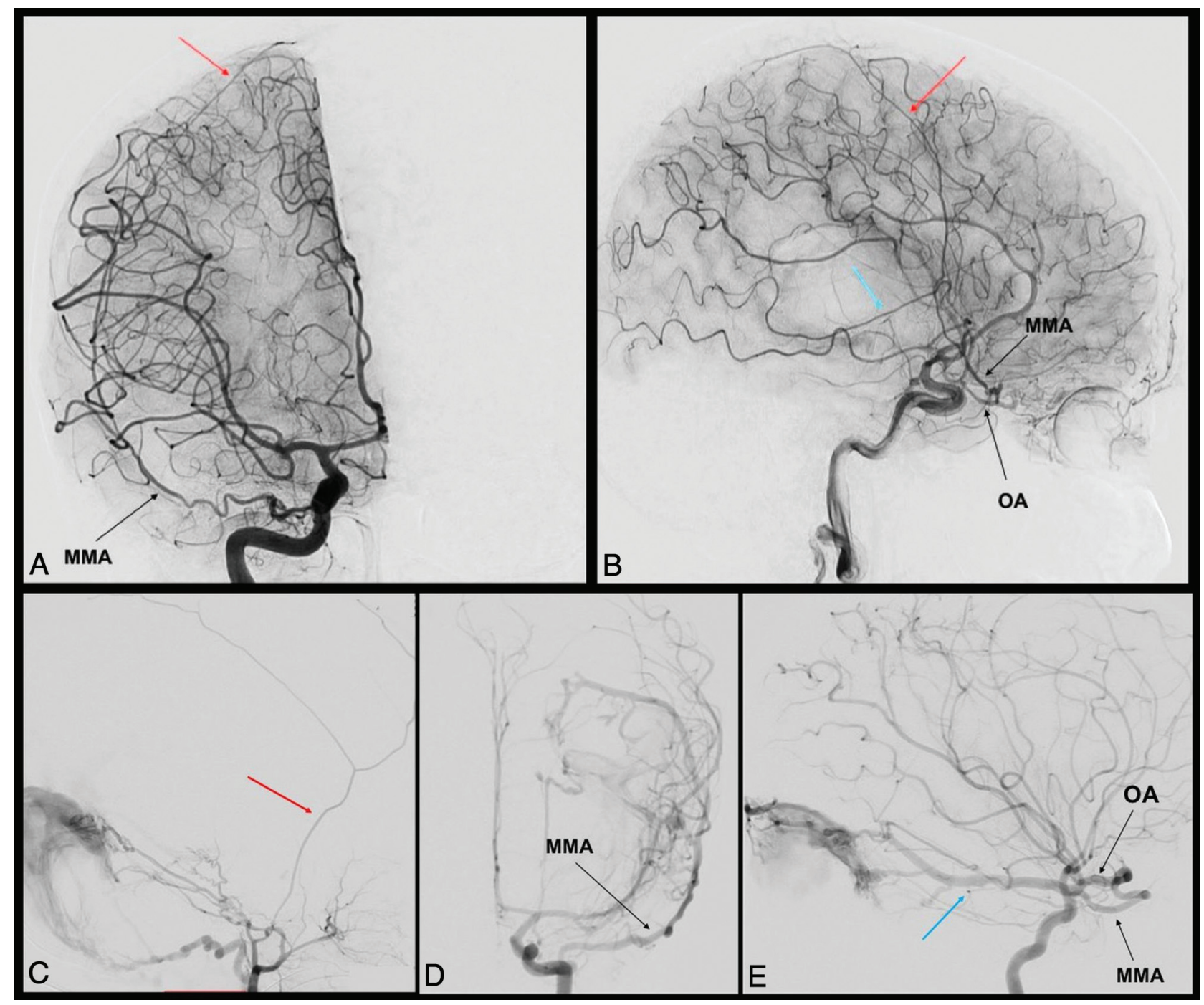

FIG 3. MMA origin from the OA. Anterior-posterior and lateral view angiograms $(A$ and $B)$ show a rare case of complete MMA origin from the $\mathrm{OA}$. The OA, through the superficial recurrent OA, gives rise to the MMA, which passes through the lateral part of the superior orbital fissure and gives off its anterior (red arrow) and posterior divisions (blue arrow). In the angiograms $C, D$, and $E$, a rare case of partial origin of the MMA from the OA is shown. The angiograms $D$ and $E$ show a left ICA injection in frontal and lateral views, where the posterior branch of the MMA (blue arrow) originates from the OA and feeds a tentorial arteriovenous fistula. After the ECA injection (C), only the anterior branch of the MMA is enhanced (red arrow). Reproduced from Bonasia et al. ${ }^{27}$

\section{Dural Supply of the OA}

The 4 meningeal branches previously described supply the dura of the cribriform plate: the planum, the anterior clinoid process, the superior orbital region, the roof and the lateral part of the cavernous sinus, the medial part of the orbital roof, and the anterior part of the falx cerebri. This vascular territory is variable, and the $\mathrm{OA}$ is in balance with other meningeal arteries of this region like the middle meningeal artery (cavernous ramus), the accessory meningeal artery, and the inferolateral trunk.

\section{Variations of Dural Branches of the Ophthalmic Artery}

Ophthalmic Artery Origin of the Middle Meningeal Artery. In rare cases, the middle meningeal artery could originate from the $\mathrm{OA}$ instead of the internal maxillary artery. The incidence of this vascular variation was estimated to be $0.5 \%$ by Dilenge and Ascherl, ${ }^{10}$ in 1980, based on a large angiographic series. A few cases of the middle meningeal artery arising from the OA have been described in the literature. The first case was presented by Curnow, ${ }^{2}$ in 1873, and in the same period, Meyer, ${ }^{1}$ in 1887, also cited 4 cadaveric cases originally described by Zuckerkandl in 1876 during a congress presentation. ${ }^{18}$ Two rare cases of this variation are shown in Fig 3. This vascular anomaly is considered the consequence of 2 different embryologic processes. The first is the failure of the supraorbital branch (stapedial artery) regression. The second is the absence of anastomosis between the maxillomandibular branch of the stapedial artery and the internal maxillary artery. Consequently, the MMA originates from the $\mathrm{OA}$ and passes through the lateral part of the superior orbital fissure; thus, the foramen spinosum is usually absent. Maiuri et al, ${ }^{19}$ in 1998, proposed 3 different types of this vascular variation as highlighted in Table 2. The first type is the complete MMA territory taken over by the OA through the superficial recurrent OA. In the second type, only the anterior branch of the MMA origin from the $\mathrm{OA}$ and the posterior branch of the MMA retain their 
origin from the internal maxillary artery. The third type is not really an OA origin of the MMA but an anastomosis between the $\mathrm{OA}$ and the accessory meningeal artery (through the deep recurrent $\mathrm{OA}$ ). The consequence is that the anterior meningeal territory is supplied by both the MMA and the OA without any communication. It is still a matter of debate whether the MMA originates from the OA directly or from the proximal part of the lacrimal artery.

Ophthalmic Artery Origin of the Marginal Tentorial Artery. The marginal tentorial artery (or artery of the free margin of the tentorium cerebelli) normally arises from the meningohypophysary trunk, but its origin is variable, as illustrated in Fig 4. This artery supplies the medial third of the tentorium, partially the walls of the cavernous sinus, and also the transdural segment of the oculomotor and trochlear nerves. ${ }^{16}$ An OA origin of this artery has been described by Lasjaunias et al, ${ }^{11}$ in 2001, distinguishing 2 different types. The first is when the marginal tentorial artery originates from the lacrimal artery. The second when the marginal tentorial artery arises directly from the OA and the lacrimal artery originates from the MMA (meningolacrimal type). A marginal tentorial artery arising from the MMA,

Table 2: Different types of OA origin of the MMA by Maiuri et $\mathrm{al}^{19}$

\begin{tabular}{|c|c|c|}
\hline Type & Vascular Anatomy & $\begin{array}{l}\text { Foramen } \\
\text { Spinosum }\end{array}$ \\
\hline $\mathrm{I}$ & Complete OA origin of the MMA & Absent \\
\hline II & $\begin{array}{l}\text { Partial OA origin of the MMA } \\
\text { Anterior division from the OA } \\
\text { Posterior division from the IMA }\end{array}$ & Reduced in size \\
\hline III & $\begin{array}{l}\text { OA origin of the accessory meningeal } \\
\text { artery }\end{array}$ & Normal \\
\hline
\end{tabular}

Note:-IMA indicates internal maxillary artery. the accessory meningeal artery or the inferolateral trunk, has also been described.

\section{Clinical Implications}

The knowledge of the dural branches arising from the OA and their variations represents the cornerstone for interventional neuroradiologists and neurosurgeons who treat anterior and middle cranial fossa pathologies. Two critical examples are cribriform plate dAVFs and anterior and middle skull base meningiomas.

Cribriform Plate Dural Arteriovenous Fistulas. The cribriform plate dAVFs are usually mostly supplied by the anterior ethmoidal artery and the MMA. A bilateral supply of the dAVF, found in approximately $10 \%$ of cases, is well-explained by the anastomoses between the 2 anterior ethmoidal arteries within the dural or ethmoidal sinuses. Endovascular treatment of such pathologies consists of the embolization, usually through branches of the MMA. The neuroradiologist has to consider the presence of dural MMA-OA anastomoses during the injection of the liquid agent to avoid retrograde flow into ocular branches of the OA. In case of direct embolization of the dAVF through the ophthalmic artery, attention should be paid to the possibility of retrograde flow of the embolic agent into ocular branches. Because the central retinal artery usually arises from the second segment of the OA, the injection should be performed as distal as possible to limit the eventual damage caused by the reflux.

The surgical exclusion of a cribriform plate dAVF also necessitates a precise knowledge of dural branches of the OA. The aim of the treatment is to exclude the cortical venous drainage of the dAVF, clipping or coagulating the draining vein at its exit point from the dura. A case of a cribriform plate dAVF treated surgically is shown in Fig 5. The knowledge of the arterioarterial anastomoses among the anterior ethmoidal, posterior ethmoidal, and middle meningeal

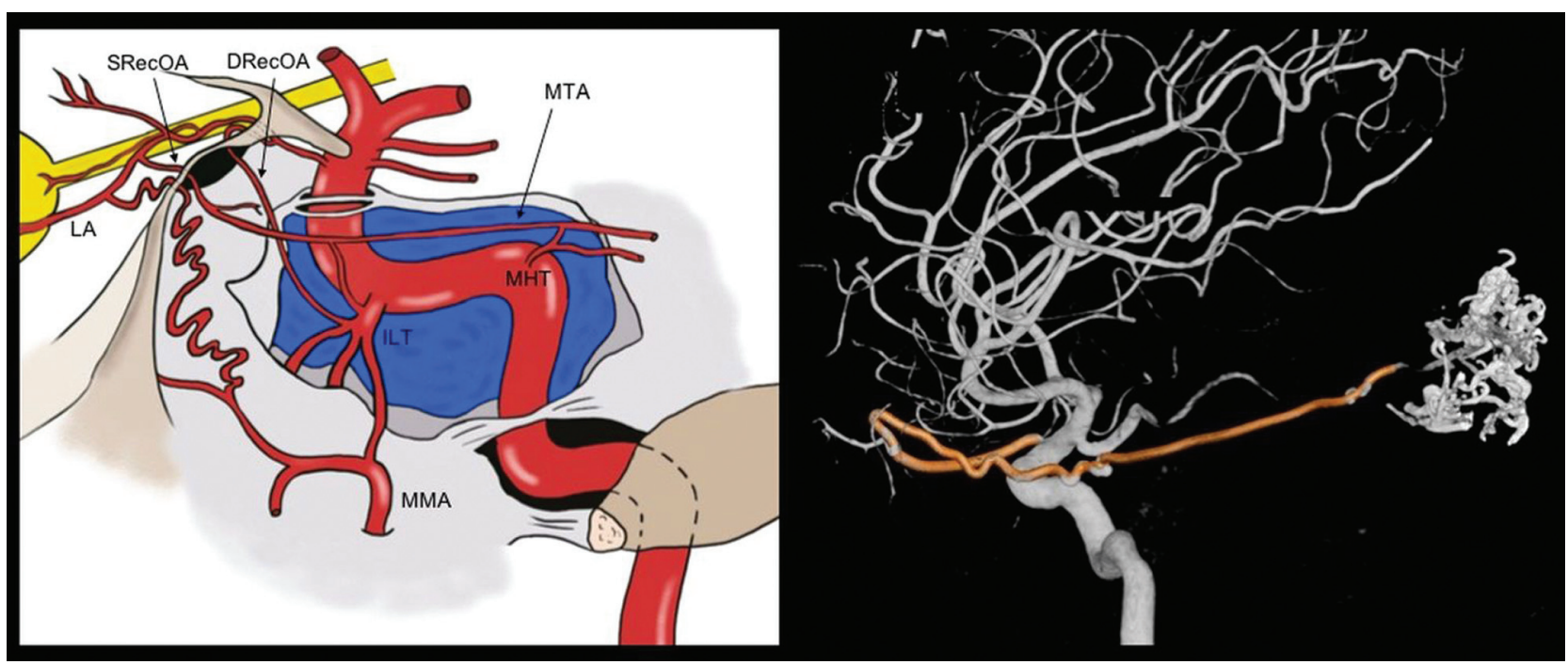

FIG 4. Marginal tentorial artery origin and course. The marginal tentorial artery, also called artery of the free margin of the tentorium or artery of Bernasconi and Cassinari, may have different origins, which are shown in the graphic representation. It can arise from the lacrimal artery (LA) within the orbit, through the superficial recurrent ophthalmic artery (SRecOA), from the inferolateral trunk (ILT), and from the meningohypophyseal trunk (MHT). The artery courses posterolaterally along the free margin of the tentorium. Note a 3D-DSA reconstruction of a rare case of MTA (highlighted in red) origin from the OA. The MTA exits the orbit through the superior orbital fissure (SOF) and is directed posteriorly to feed an arteriovenous malformation. DRecOA indicatesdeep recurrent ophthalmic artery . 


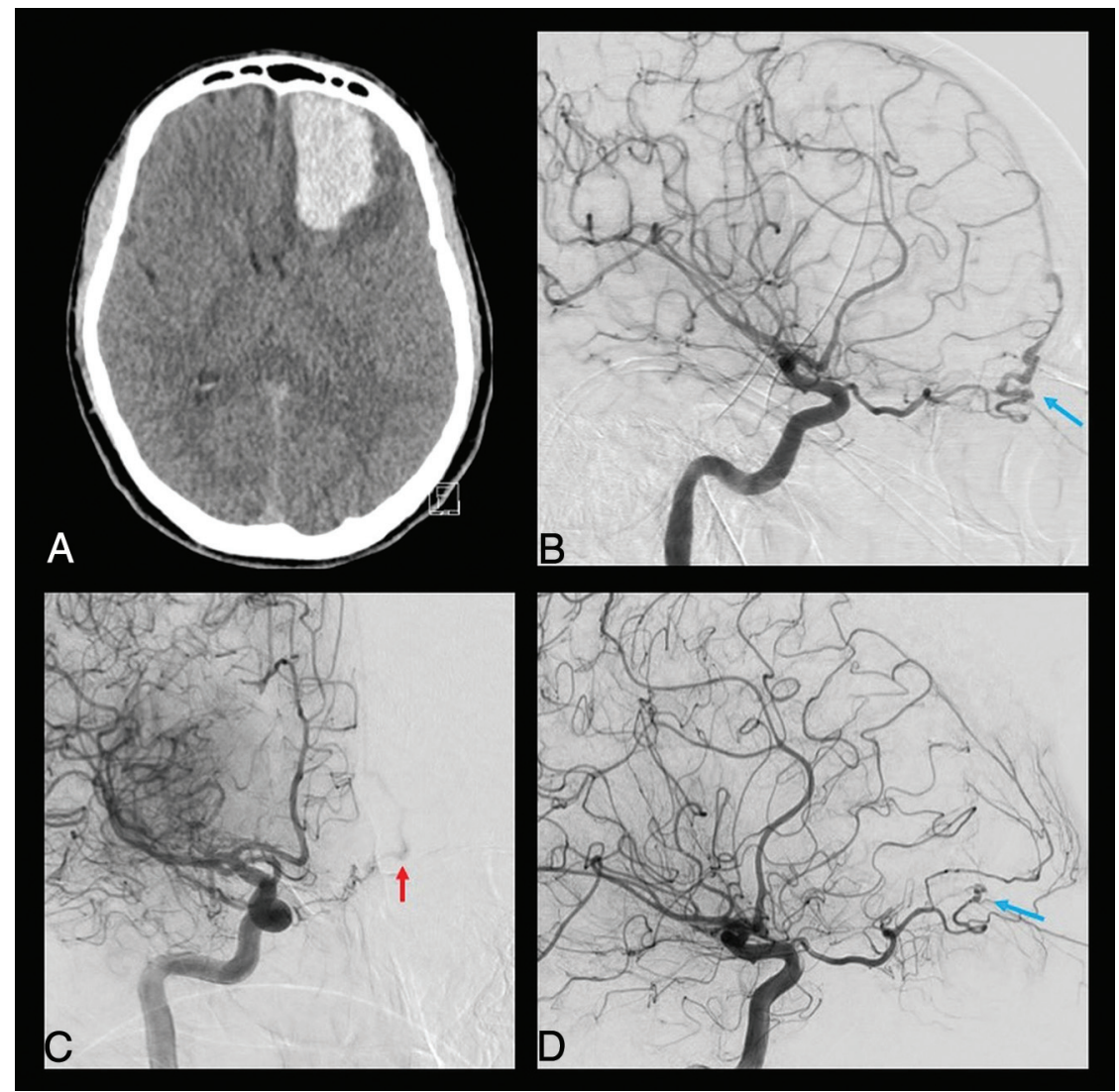

FIG 5. Clinical case of a ruptured cribriform plate dAVF. A 49-year-old man was admitted for sudden onset of unusual headache with nausea and vomiting. The CT scan performed in the emergency department $(A)$ shows a left frontal basis intraparenchymal hematoma. The DSA highlighted a cribriform plate dAVF with major feeders represented by the left anterior ethmoidal artery from the left OA (blue arrow in $B$ ). The right ICA injection also showed a contribution from the contralateral OA through its ethmoidal branches (red arrow in C). The venous drainage was represented by a single cortical vein directed into the superior sagittal sinus (type III according to the Cognard-Lariboisière classification ${ }^{26}$ ). The patient successfully underwent left supraorbital craniotomy and clipping of the dAVF (D), with no enhancement of the dAVF on the postoperative DSA (blue arrow) and complete clinical recovery.
In case of an operation in a middle cranial fossa meningioma, the devascularization of the tumor as a first step could be helpful to better understand the arterial supply of the lesion and limit drastically blood loss.

Intra-arterial Injection of Chemotherapy for Retinoblastoma. The classic technique used to inject chemotherapeutic agents into the OA for the treatment of retinoblastoma requires the superselective catheterization of the $\mathrm{OA}^{20}$ However, the knowledge of OA dural branches acquires a more important role when the direct catheterization of the $\mathrm{OA}$ is not possible, as can happen in children due to its reduced size. In these cases, alternative ways to reach the OA indirectly have been described, ${ }^{21}$ especially through catheterization of the MMA. Thus, the pharmacologic agents can be injected through the anterior division of the MMA, cannulating its meningolacrimal branch. The reflux into the OA could be from anastomoses between MMA orbital branches and the recurrent branches of the OA, from the lacrimal artery, or sometimes from the direct origin of the OA from the MMA.

Surgical and Endovascular Treatarteries is necessary to understand the dAVF and the technical difficulties of the treatment. Another case of a dAVF fed by dural branches of the OA is shown in Fig 6, also with a contribution from the MTA.

The knowledge of the dural branches of the OA and MMA origin from the OA also adequately explains the possible participation of OA branches in the supply of carotid-cavernous fistulas or tentorial pathologies (Figs 3 and 4).

Anterior and Middle Cranial Fossa Meningiomas. The surgical removal of cribriform plate or sphenoid wing meningiomas requires a detailed knowledge of vascular normal anatomy and tumor vascular supply. Meningeal tumors of the anterior and middle skull base are usually supplied by dural branches of the MMA, internal carotid artery, and the ophthalmic artery. It is of paramount importance for interventional neuroradiologists who plan an embolization, usually performed through the MMA, to consider the possible variations in the supply of the skull base dura to avoid involuntary OA reflux of embolic liquid agent. ment of Refractory Epistaxis. Re-fractory epistaxis may be caused by many clinical conditions and occurs in about $60 \%$ of the adult population, with most cases considered idiopathic. Among them, about $6 \%$ of the epistaxis is refractory to conservative management and requires surgical or interventional treatment. $^{22}$

The best way to understand the source of bleeding in case of refractory epistaxis is to perform a diagnostic DSA including the ICA and ECA. The DSA allows identifying the so called "vascular blush," an anastomotic plexus located in the nasal septum, considered the source of $90 \%$ of epistaxis. The sphenopalatine artery represents its main blood supply, and it is most commonly responsible for refractory epistaxis, even if, in rare cases, the ethmoidal arteries could also be involved. ${ }^{23}$ If these latter are involved in the bleeding, they can be ligated through a surgical approach. On the other hand, if the sphenopalatine artery is responsible for bleeding, it can be occluded through an endonasal approach or it can be embolized. ${ }^{23}$ 


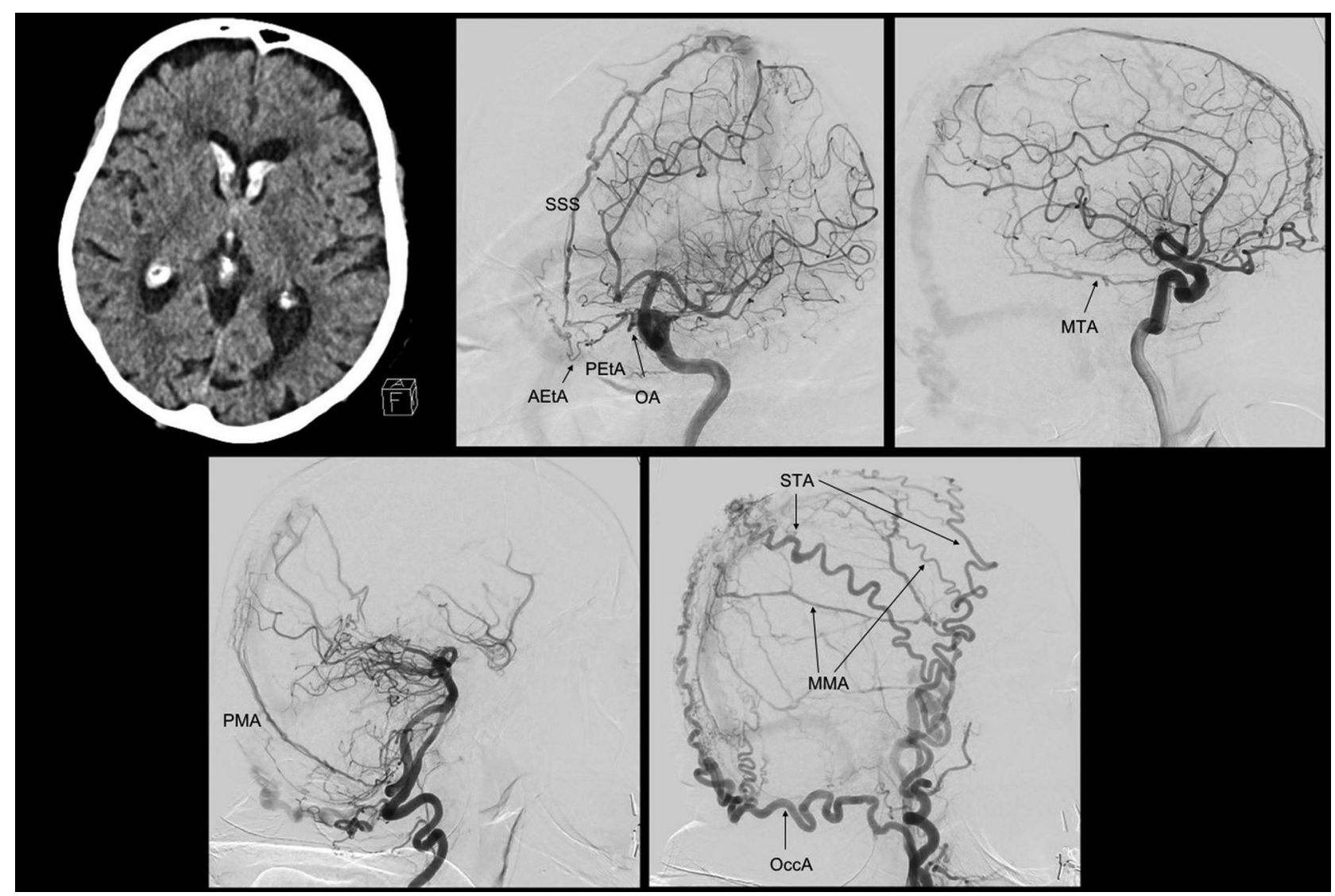

FIG 6. Clinical case of a dAVF fed by multiple OA dural branches. An 89-year-old woman, previously having undergone an operation for a pituitary adenoma, was admitted for unusual headache associated with vomiting. The CT scan shows an intraventricular hemorrhage with mild hydrocephalus. The diagnostic DSA shows a complex dAVF (Cognard-Lariboisière grade Ila $+b^{26}$ ) supplied by the OA through the anterior and posterior ethmoidal arteries (AEtA, PEtA), with both direct and indirect shunts with the superior sagittal sinus (SSS). Another point of shunt with the SSS is reached by the MTA and the posterior meningeal artery (PMA) and the MMA. Also, other branches from the ECA contribute to the shunt, like the occipital artery (OccA) and the superficial temporal artery (STA). Because of the patient's age, the complexity of the dAVF, the high risk associated with every option of treatment, and the absence of alteration of consciousness, we managed the dAVF conservatively.

The diagnostic DSA allows identifying possible dangerous anastomoses between branches of the ECA and the OA, which can result in postembolization visual or central deficits. The occurrence of cerebrovascular accidents and obstruction of the central retinal artery have been described to occur in about $0 \%-2 \%$ of cases. ${ }^{24}$ The most important anastomoses to consider during such procedures are between the sphenopalatine and anterior ethmoidal arteries via the turbinate and infraorbital arteries ${ }^{23}$ and between the lacrimal artery and the middle meningeal artery through the recurrent meningeal artery. ${ }^{24}$ The relevance of these anastomoses and the periprocedural risk can be estimated by analyzing the "choroidal blush." This blush is commonly visualized after contrast injection into the ICA. However, if the anastomoses among the posterior ciliary arteries, the lacrimal artery, and the MMA are very consistent or if the lacrimal artery and the OA branch directly from the MMA, the choroidal blush can be seen after the ECA injection. ${ }^{24}$

Embolization of Facial Tumors. Even if epistaxes are mostly idiopathic, some cases can be due to neoplastic erosion of vascular structures or as result of tumor necrosis after treatment. In these cases, the symptoms can also cause hemoptysis due to the frequent nasopharyngeal localization of these tumors. Endovascular treatment should be considered in these cases to treat uncontrollable epistaxis or hemoptysis. Also benign tumors, like paragangliomas and nasopharyngeal angiofibromas, can benefit from endovascular embolization as a preoperative procedure to reduce the intraoperative blood loss. In these cases, the embolization of the sphenopalatine artery could be insufficient, and devascularization requires the embolization of the facial artery and ascending pharyngeal artery. ${ }^{23}$ In these cases, neuroradiologists should pay attention to the known anastomoses between the facial artery and the dorsal nasal artery (through the angular artery). ${ }^{25}$ For these pathologies, the neuroradiologists should observe the same rules as previously described to avoid complications due to ICA-ECA anastomoses. ${ }^{23}$

In conclusion, the knowledge of the embryology and anatomy of the dural branches of the OA is mandatory for treating pathology of the dura mater located in the anterior and middle cranial fossae. These arteries show high variability and supply territories 
in competition with the middle meningeal artery and internal carotid artery branches.

\section{REFERENCES}

1. Meyer F. Zur anatomie der Orbitalarteien. Morph Jahr 1887;12:414-58

2. Curnow J. Two instances of irregular ophthalmic and middle meningeal arteries. J Anat Physiol 1873;8:155-56 Medline

3. Kuru Y. Meningeal branches of the ophthalmic artery. Acta Radiol Diagn (Stockh) 1967;6:241-51 CrossRef Medline

4. Gabriele OF, Bell D. Ophthalmic origin of the middle meningeal artery. Radiology 1967;89:841-44 CrossRef Medline

5. Royle G, Motson R. An anomalous origin of the middle meningeal artery. J Neurol Neurosurg Psychiatry 1973;36:874-76 CrossRef Medline

6. McLennan JE, Rosenbaum AE, Haughton VM. Internal carotid origins of the middle meningeal artery: the ophthalmic-middle meningeal and stapedial-middle meningeal arteries. Neuroradiology 1974;7:265-75 CrossRef Medline

7. Vignaud J, Hasso AN, Lasjaunias $P$, et al. Orbital vascular anatomy and embryology. Radiology 1974;111:617-26 CrossRef Medline

8. Lasjaunias P, Moret J, Manelfe C, et al. Arterial anomalies at the base of the skull. Neuroradiology 1977;13:267-72 CrossRef Medline

9. Lasjaunias P, Brismar J, Moret J, et al. Recurrent cavernous branches of the ophthalmic artery. Acta Radiol Diagn (Stockh) 1978;19:55360 CrossRef Medline

10. Dilenge D, Ascherl GF Jr. Variations of the ophthalmic and middle meningeal arteries: relation to the embryonic stapedial artery. AJNR Am J Neuroradiol 1980;1:45-54 Medline

11. Lasjaunias P, Bereinstein A, Ter Brugge KG. Surgical Neuroangiography. Springer-Verlag; 2001

12. Rhoton AL Jr. The orbit. Neurosurgery 2002;51:S303-34 CrossRef Medline

13. Padget $\mathrm{DH}$. The development of cranial arteries in the human embryo. In: Corner G, ed. Contributions to Embryology. Carnegie Institution; 1948:205-62

14. Lasjaunias $P$, Moret J, Mink J. The anatomy of the inferolateral trunk (ILT) of the internal carotid artery. Neuroradiology 1977;13:215-20 CrossRef Medline
15. Hayreh SS. The ophthalmic artery, III: branches. Br J Ophthalmol 1962;46:212-47 CrossRef Medline

16. Martins C, Yasuda A, Campero A, et al. Microsurgical anatomy of the dural arteries. Neurosurgery 2005;56:211-51; discussion 211-51 CrossRef Medline

17. Lang J, Kageyama I. The ophthalmic artery and its branches, measurements and clinical importance. Surg Radiol Anat 1990;12:83-90 CrossRef Medline

18. Zuckerkandl E. Zur Anatomie der Orbita Arterien. Med Jahr 1876:343

19. Maiuri F, Donzelli R, de Divitiis O, et al. Anomalous meningeal branches of the ophthalmic artery feeding meningiomas of the brain convexity. Surg Radiol Anat 1998;20:279-84 CrossRef Medline

20. Yamane T, Kaneko A, Mohri M. The technique of ophthalmic arterial infusion therapy for patients with intraocular retinoblastoma. Int J Clin Oncol 2004;9:69-73 CrossRef Medline

21. Klufas MA, Gobin YP, Marr B, et al. Intra-arterial chemotherapy as a treatment for intraocular retinoblastoma: alternatives to direct ophthalmic artery catheterization. AJNR Am J Neuroradiol 2012;33:1608-14 CrossRef Medline

22. Christensen NP, Smith DS, Barnwell SL, et al. Arterial embolization in the management of posterior epistaxis. Otolaryngol Head Neck Surg 2005;133:748-53 CrossRef Medline

23. Reyre A, Michel J, Santini L, et al. Epistaxis: the role of arterial embolization. Diagn Interv Imaging 2015;96:757-73 CrossRef Medline

24. Mames RN, Snady-McCoy L, Guy J. Central retinal and posterior ciliary artery occlusion after particle embolization of the external carotid artery system. Ophthalmology 1991;98:527-31 CrossRef Medline

25. Bertelli E, Regoli M, Bracco S. An update on the variations of the orbital blood supply and hemodynamic. Surg Radiology Anat 2017;39:485-96 CrossRef Medline

26. Cognard C, Gobin YP, Pierot L, et al. Cerebral dural arteriovenous fistulas: clinical and angiographic correlation with a revised classification of venous drainage. Radiology 1995;194:671-80 CrossRef Medline

27. Bonasia S, Smajda S, Ciccio G, et al. Middle meningeal artery: anatomy and variations. AJNR Am J Neuroradiol 2020;41:1777-85 CrossRef Medline 